\title{
CORRECTION
}

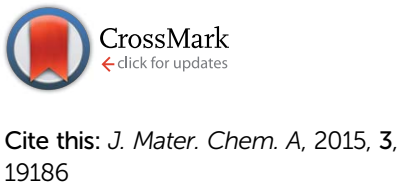

DOI: $10.1039 / c 5 \operatorname{ta} 90195 b$

www.rsc.org/MaterialsA

\section{Correction: Low-cost and high energy density asymmetric supercapacitors based on polyaniline nanotubes and $\mathrm{MoO}_{3}$ nanobelts}

\author{
Hui Peng, ${ }^{a}$ Guofu Ma, ${ }^{* a}$ Jingjing Mu, ${ }^{a}$ Kanjun Sun ${ }^{\mathrm{b}}$ and Ziqiang Lei ${ }^{\star a}$
}

Correction for 'Low-cost and high energy density asymmetric supercapacitors based on polyaniline nanotubes and $\mathrm{MoO}_{3}$ nanobelts' by Hui Peng et al., J. Mater. Chem. A, 2014, 2, 10384-10388.

The following sentence on page 10387 is incorrect: "According to the formula of specific capacitance (ESI $\dagger$ ), the gravimetric capacitance of PANI//MoO ${ }_{3}$ ASCs is as high as $518 \mathrm{~F} \mathrm{~g}^{-1}$ at a current density of $0.5 \mathrm{~A} \mathrm{~g}^{-1}$, which is much higher than those recently reported for other ASCs, such as RGO-RuO $/ /$ RGO-PANI (about $360 \mathrm{~F} \mathrm{~g}^{-1}$ at $\left.0.3 \mathrm{Ag}^{-1}\right){ }^{13} \mathrm{GrMnO}_{2} / / \mathrm{GrMoO}_{3}\left(307 \mathrm{~F} \mathrm{~g}^{-1} \text { at } 0.2 \mathrm{Ag}^{-1}\right)^{14}$ and $\mathrm{Ni}(\mathrm{OH})_{2} / \mathrm{UGF} / / \mathrm{a}-\mathrm{MEGO}\left(119 \mathrm{~F} \mathrm{~g}^{-1}\right.$ at $\left.1 \mathrm{~A} \mathrm{~g}^{-1}\right)$. $^{32,}$.

This should read "According to the formula of specific capacitance (ESI $\dagger$ ), the gravimetric capacitance of one electrode in the $\mathrm{PANI} / \mathrm{MoO}_{3}$ ASCs is as high as $518 \mathrm{~F} \mathrm{~g}^{-1}$ at a current density of $0.5 \mathrm{~A} \mathrm{~g}^{-1}$, which is much higher than those recently reported for other ASCs, such as RGO-RuO $/ / /$ RGO-PANI (about $360 \mathrm{~F} \mathrm{~g}^{-1}$ at $\left.0.3 \mathrm{~A} \mathrm{~g}^{-1}\right),{ }^{13} \mathrm{GrMnO}_{2} / / \mathrm{GrMoO}_{3}\left(307 \mathrm{~F} \mathrm{~g}^{-1} \text { at } 0.2 \mathrm{~A} \mathrm{~g}^{-1}\right)^{14}$ and $\mathrm{Ni}(\mathrm{OH})_{2} / \mathrm{UGF} / / \mathrm{a}-\mathrm{MEGO}\left(119 \mathrm{~F} \mathrm{~g}^{-1}\right.$ at $\left.1 \mathrm{~A} \mathrm{~g}^{-1}\right) .{ }^{32,}$

The Royal Society of Chemistry apologises for these errors and any consequent inconvenience to authors and readers.

${ }^{a}$ Key Laboratory of Eco-Environment-Related Polymer Materials of Ministry of Education, Key Laboratory of Polymer Materials of Gansu Province, College of Chemistry and Chemical Engineering, Northwest Normal University, Lanzhou 730070, China. E-mail: magf@nwnu.edu.cn; Fax: +86-931-7975121; Tel: +86-931-7975121

${ }^{b}$ College of Chemistry and Environmental Science, Lanzhou City University, Lanzhou 730070, China 